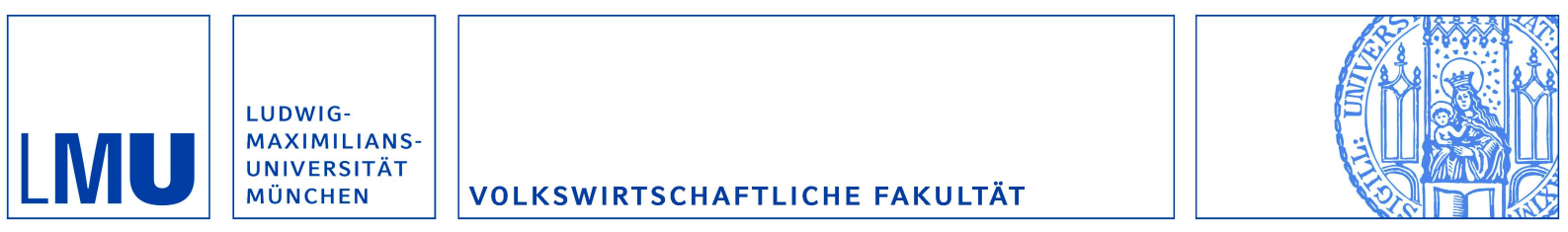

Krieger, Tim:

Fertility Rates and Skill Distribution in Razin and Sadka's Migration-Pension Model: A Note

Munich Discussion Paper No. 2003-20

Department of Economics

University of Munich

Volkswirtschaftliche Fakultät

Ludwig-Maximilians-Universitäł München

Online at https://doi.org/10.5282/ubm/epub.82 


\title{
Fertility rates and skill distribution in Razin and Sadka's migration-pension model: a note ${ }^{1}$
}

\author{
Tim Krieger \\ Ludwig-Maximilians-Universität München, Germany
}

August 2003

\begin{abstract}
Razin and Sadka (1999) show that unskilled immigration is beneficial to all income and all age groups in society, even if immigrants are net beneficiaries of the welfare system. Among other things, this result rests on the assumptions that immigrants have the same reproduction rate as the native population and that the immigrants' offspring has the same distribution of skills as the natives' offspring. By relaxing these assumptions, we show that the Razin and Sadka result is no longer unambiguous.
\end{abstract}

Keywords: fertility rates, immigration policy, public pensions

JEL-Classification: H55, J61

\section{Address for correspondence}

Tim Krieger, Seminar für Wirtschaftspolitik, Ludwig-Maximilians-Universität München, Akademiestr. 1 / II, 80799 München, Germany, Phone: ++49-89-2180 2249, Fax: ++49-89-2180 6296, email: tim.krieger@lrz.uni-muenchen.de.

${ }^{1}$ Helpful comments and suggestions from two anonymous referees are gratefully acknowledged. 


\section{Introduction}

In most OECD countries, pay-as-you-go financed pension systems suffer from demographic problems. From the ageing of societies it inevitably follows that either pension benefits must fall or contribution rates must increase. Because of this, immigration of young workers has frequently been proposed as a means to overcome the ageing problem. It increases the number of contributors to the pension system which helps to dampen the negative effects of ageing on contribution rates and benefits. This argument has been formalized by Razin and Sadka $(1999,2000)^{2}$ who introduced a model in which they investigate the impact of young unskilled immigration on the pension system in an OLG model with two generations. They find that in this dynamic setup immigration is beneficial to all income and to all age groups (or at least, it does not harm any group), even if the immigrants are net beneficiaries of the welfare system. The reason for this result is that the net costs imposed by the immigrants are transferred into the indefinite future. Hence, in a politico-economic sense all generations will vote in favor of immigration.

The model, however, rests on several rather strong assumptions. In this note, we will mainly turn to the assumption that the reproduction rates of natives and immigrants are equalized as soon as the immigrants enter the country and that the joint rate will be the natives' one. Furthermore, we relax the assumption that the ability (in the sense of acquired destination country-specific human capital) of the immigrant's offspring is distributed identically to that of the natives. Therefore, we will allow for (i) differing fertility rates between natives and immigrants and (ii) different skill distribution of the natives' and the immigrants' offspring.

We find that under real-world assumptions, i.e. immigrants having a higher fertility rate than natives and the skill distribution being skewed in favor of the natives, there are two offsetting effects on the expected pension benefit of today's working generation. Depending on the parameter values, either the positive fertility effect or the negative skill effect will dominate and cause the workers either to accept or to reject young unskilled immigration. Hence, even if interest rates and wages are constant (as in RS) two externalities result from immigration: A positive one

\footnotetext{
${ }^{2}$ We refer to these articles from now on as RS.
} 
on the domestic retirees due to higher total contributions and an ambiguous one on domestic workers and future generations which depends on the two before mentioned effects. If in total a positive redistributive effect towards the domestic population occurs, one can consider this to be an "entrance fee", as Sinn (2001) puts it, for the immigrants.

\section{Labor supply}

In the following, we will use a simplified version of RS's model in which we neglect the education decision of workers. It is assumed that there are two groups of homogenous workers in the beginning. The population is normalized to unity. Let $s_{t}$ be the share of skilled workers, and let $u_{t}$ be the share of unskilled workers. So, we have $s_{t}+u_{t}=1$. There are $m_{t}$ immigrants allowed into the country in period $t$, which are assumed to be unskilled.

The effective labor supply in $t$ is given by

$$
L_{t}=s_{t}+q u_{t}+q m_{t}=(1-q) s_{t}+\left(1+m_{t}\right) q,
$$

where $q<1$, i.e. unskilled workers provide only $q$ units of effective labor per unit of working time, and where $u_{t}$ is substitued by $1-s_{t}$.

In contrast to $\mathrm{RS}$, we assume that fertility rates between natives and immigrants may differ. We call the native's rate $n_{t}$ and the immigrant's rate $\widetilde{n}_{t}$, so RS assume: $n_{t}=$ $\tilde{n}_{t} \cdot{ }^{3}$ Furthermore, we assume that a share $\alpha$, where $\alpha \in\left[0, s_{t}\right]$, of the immigrant's offspring will become skilled in period $t+1$. This means that the share of unskilled children of immigrants ranges between the level of the native population, which is $1-s_{t}$, and unity. ${ }^{4}$ Or to put it the other way round: we assume that in the long

\footnotetext{
${ }^{3}$ The assumption is quite common in this strand of the literature (see Krieger (2001) for a survey of the recent literature on immigration and pensions).

${ }^{4} \mathrm{We}$ can interpret this assumption in the following way: It takes some (costless) integration effort on the part of the natives to have the immigrant's offspring attain the same skill distribution as the native's offspring, e.g. by communicating with the immigrants' children in order to help them improve their language skills etc. If no integration effort takes place, the entire immigrants' offspring remains unskilled. Otherwise, at least some percentage of the immigrants' children will become skilled, i.e. they will be able to compete with skilled natives for jobs.
} 
run it is not possible for immigrants to perform better than natives (in the sense of becoming skilled workers). ${ }^{5}$ The parameter $\alpha$ is exogenously given and may differ between societies.

The effective labor supply in $t+1$ turns out to be

$$
\begin{aligned}
L_{t+1} & =s_{t+1}+q u_{t+1} \\
& =s_{t}\left(1+n_{t}\right)+\alpha m_{t}\left(1+\widetilde{n}_{t}\right)+q\left[u_{t}\left(1+n_{t}\right)+(1-\alpha) m_{t}\left(1+\widetilde{n}_{t}\right)\right] \\
& =\left(1+n_{t}\right)\left[(1-q) s_{t}+q\right]+\left(1+\widetilde{n}_{t}\right) m_{t}[(1-q) \alpha+q] .
\end{aligned}
$$

We can easily derive RS's result by taking $n_{t}=\widetilde{n}_{t}$ and $\alpha=s_{t}$. Then, equation (2) collapses to $L_{t+1}=\left(1+n_{t}\right)\left(1+m_{t}\right)\left[s_{t}+q u_{t}\right]$.

\section{The pension system}

As in RS, we assume that in each period $t$ workers pay contributions to the pension system which are transferred to the retirees as demogrant benefits $p_{t}$. Contributions take the form of a payroll tax where $\tau_{t}$ is the tax rate per unit of income. Hence, in period $t$ the budget equation of the pay-as-you-go pension system is given by

$$
\tau_{t} w_{t}\left(s_{t}+q\left(u_{t}+m_{t}\right)\right)=p_{t}\left(s_{t-1}+u_{t-1}\right)
$$

where the bracketed terms are the relevant labor supplies in each period. Making use of $(1)$ and the fact that $\left(s_{t}+u_{t}\right)=\left(1+n_{t-1}\right)\left(s_{t-1}+u_{t-1}\right)$, we can solve $(3)$ for $p_{t}$ :

$$
p_{t}=\left(1+n_{t-1}\right) \tau_{t} w_{t}\left[(1-q) s_{t}+\left(1+m_{t}\right) q\right]
$$

Taking the derivative with respect to immigration $m_{t}$ shows that an increasing number of immigrants raises the pension benefit $\left(\frac{\partial p_{t}}{\partial m_{t}}=\left(1+n_{t-1}\right) \tau_{t} w_{t} q>0\right)$. This is because, for a given contribution rate, immigration increases total contributions.

\footnotetext{
${ }^{5}$ This may be due to the fact that both groups will attend the same school system.
} 
A constant number of retirees will therefore enjoy higher benefits. Retirees in period $t$ will in any case gain from immigration.

Turning now to the situation in period $t+1$, we can derive a new budget equation of the pension system. To do so, we have to take into account the labor supply from equation (2):

$$
\tau_{t+1} w_{t+1}\left\{\left(1+n_{t}\right)\left[(1-q) s_{t}+q\right]+\left(1+\widetilde{n}_{t}\right) m_{t}[(1-q) \alpha+q]\right\}=p_{t+1}\left(s_{t}+u_{t}+m_{t}\right)
$$

Notice that $s_{t}+u_{t}=1$ on the right-hand side. Hence, solving for $p_{t+1}$ leaves us with

$$
p_{t+1}=\tau_{t+1} w_{t+1} \frac{\left(1+n_{t}\right)\left[(1-q) s_{t}+q\right]+\left(1+\widetilde{n}_{t}\right) m_{t}[(1-q) \alpha+q]}{1+m_{t}} .
$$

Again, the RS result can be established by assuming $n_{t}=\widetilde{n}_{t}$ and $\alpha=s_{t}$. Then the pension benefit is $p_{t+1}=\tau_{t+1} w_{t+1}\left(1+n_{t}\right)\left[s_{t}+q u_{t}\right]$.

Taking the derivative of (6) with respect to $n_{t}, \widetilde{n}_{t}, s_{t}, q$, and $\alpha$ gives the expected positive signs. If either one of the two reproduction rates increases, there will be more contributors to the pension system, i.e. the demogrant benefit increases. If the share of skilled workers in the total population increases or if the productivity $q$ of unskilled workers is raised (e.g. due to an improved school system), the effective labor supply is higher and therefore total contributions are higher. Finally, if the parameter $\alpha$ becomes higher (e.g. due to special training for immigrants), a larger share of the immigrant's offspring becomes skilled. Again, the productivity improves. Let us now investigate whether the overall impact of immigration on the pension benefit in period $t+1$ is positive. The first-order condition can be written as

$$
\begin{aligned}
\frac{\partial p_{t+1}}{\partial m_{t}}= & \frac{\tau_{t+1} w_{t+1}}{\left(1+m_{t}\right)^{2}}\left\{\left(1+\widetilde{n}_{t}\right)\left(1+m_{t}\right)[(1-q) \alpha+q]\right. \\
& \left.-\left[\left(1+n_{t}\right)\left[(1-q) s_{t}+q\right]-\left(1+\widetilde{n}_{t}\right) m_{t}[(1-q) \alpha+q]\right]\right\} .
\end{aligned}
$$

Simplifying this expression, we find that there is a positive impact of immigration on $p_{t+1}$, i.e. $\frac{\partial p_{t+1}}{\partial m_{t}}>0$, if the following condition holds: 


$$
\frac{\left(1+\widetilde{n}_{t}\right)}{\left(1+n_{t}\right)}>\frac{(1-q) s_{t}+q}{(1-q) \alpha+q} .
$$

We can look at some special cases to see the implications of equation (8). Let us first consider the RS assumptions, i.e. $n_{t}=\widetilde{n}_{t}$ and $\alpha=s_{t}$. Clearly, both sides of (8) equal 1 , so immigration has no impact on pension benefits in period $t+1$. This is just the result derived by $\mathrm{RS}$ who show that immigration in period $t$ leaves all generations retiring in $t+1$ or later indifferent.

We now relax the assumption that the fertility rates have to be the same. It is reasonable, at least for unskilled immigrants, to assume $n_{t}<\widetilde{n}_{t}{ }^{6}$ Taking the RS case as a starting point, the left-hand side of (8) now increases and exceeds the right-hand side. Hence, not only the retirees of the immigration period $t$ (as in RS) gain from immigration, but also the young and future generations. ${ }^{7}$

One can also keep the equality of fertility rates and allow for differences in the skill distribution of both groups' offspring. The right-hand side of (8) is 1 if the upper limit of the domain of $\alpha$ is attained, i.e. if $\alpha=s_{t}$. If $0 \leq \alpha<s_{t}$, the right-hand side becomes greater than 1 . So, for $n_{t}=\widetilde{n}_{t}$, any $\alpha<s_{t}$ causes a negative impact of immigration on the pension benefit. The reason for this result is that due to immigration the share of unskilled workers increases in period $t+1$ compared to the one in period $t$. The effective labor supply falls and the native workers have to carry some of the burden of the immigrants. ${ }^{8}$ This is because an average immigrant's child contributes less to the pension system than an average native child. But at the same time, the pension benefit is the same for natives and immigrants. Hence, some

\footnotetext{
${ }^{6}$ Storesletten (2000) finds that the average total fertility rate for medium- and low-skilled immigrants to the U.S. is 7 percent and 50 percent, respectively, higher than for natives. For high-skilled immigrants, however, it is 16 percent lower.

${ }^{7}$ Within the RS framework one could also argue in the following way: If migration is perpetually taking place, then migration with the same fertility rate for migrants as for the native population is equivalent to a one-shot migration with migrants having higher fertility rates and leads to a gain for future generations.

${ }^{8}$ In addition to this effect the skill level of natives in $t+1$ may also fall due to unskilled immigration. This may be the case e.g. if school teachers need to put a high effort into improving the language skills of immigrant children, thereby slowing down the pace of instruction. Then, the effective labor supply will fall even further.
} 
redistribution takes place between natives and immigrants.

Obviously, there are two counteracting effects: On the one hand, immigration may have a positive effect on pension benefits in future periods due to relatively higher fertility rates. On the other hand, immigration that is followed by a relatively poor performance of immigrants' children in attaining destination country-specific human capital leads to falling pension benefits in $t+1$.

\section{Voting outcome and conclusions}

The voting outcome in period $t$ can easily be derived. Let us first turn to the retirees who maximize their pension benefit $p_{t}$ (according to equation (4)) with respect to the level of immigration. We have already seen that immigration increases the pension benefit, so the retirees will be in favor of boundless immigration. Turning to the group of workers active in period $t$, the situation changes. As the model assumes that the marginal products of factor inputs do not change, today's wages remain constant in the face of immigration. So, only the (discounted) future pension benefit plays a role in their optimization problem. Under the assumptions of the RS model, workers are indifferent with regard to immigration. However, considering differing reproduction rates and skill distributions, we find that their voting behavior depends on the parameter values for $\widetilde{n}$ and $\alpha$. If the positive effect of relatively higher fertility of immigrants more than offsets the negative effect of a relatively low skill level of the immigrants' offspring, allowing immigrants into the country will be the optimal choice. If, however, the negative effect dominates, zero immigration will be voted for. The decision of the working generation constitutes the final voting outcome if we assume that the working generation is greater than the retired generation.

So, even if one does not consider any negative impact of immigration on gross wages, it may be possible - unlike in RS where no generation will lose from immigration

- that zero immigration is the voting outcome. If one allows for a falling marginal productivity of (unskilled) labor due to unskilled immigration, however, the young and future generations are clearly hurt, as was shown in the simulation analysis in Razin and Sadka (2000). This is also the driving force in other studies on the fiscal consequences of unskilled immigration, such as Canova and Ravn (1998). They find 
that the previously existing level of redistribution to the unskilled can no longer be sustained under these circumstances.

But even if wages drop, our findings show that a welfare gain may nevertheless occur: When there is a strong positive effect on future pension benefits through very high fertility rates of the immigrants or a high skill level, then even a negative impact of immigration on wages may be compensated. ${ }^{9}$ This is in line with Storesletten (2000) who finds in a more general framework that the fiscal problems associated with the aging of the baby boom generation in the U.S. may be overcome by immigration alone if the age and skill distribution as well as the number of immigrants is chosen properly. ${ }^{10}$

\section{References}

Canova F, Ravn M (1998) Crossing the Rio Grande: Migrations, Business Cycles and the Welfare State. CEPR Discussion Paper No. 2040, London

Krieger T (2001) Intergenerational Redistribution and Labor Mobility: A Survey. FinanzArchiv 58(3): 339-361

Razin A, Sadka E (1999) Migration and Pension with International Capital Mobility. Journal of Public Economics 74(1): 141-150

Razin A, Sadka E (2000) Unskilled Migration: A Burden or a Boon for the Welfare State. Scandinavian Journal of Economics 102(3): 463-479

Sinn HW (2001) The Value of Children and Immigrants in a Pay-As-You-Go Pension System: A Proposal for a Partial Transition to a Funded System. ifo Studien 47(1): 77-94

Storesletten K (2000) Sustaining Fiscal Policy through Immigration. Journal of Political Economy 108(2): 300-323

\footnotetext{
${ }^{9}$ Here, a sufficiently low immigration elasticity with respect to gross wages needs to be assumed.

${ }^{10}$ This implies a reasonable increase of annual immigration from 0.44 to 0.62 percent of the population, provided that the new immigrants are high-skilled and between 40 and 44 years old (Storesletten, 2000).
} 